\title{
Léon Blum - André Gide, Correspondance 1890-1951
}

\section{Gian Luigi Di Bernardini}

\section{(2) OpenEdition}

\section{Journals}

\section{Edizione digitale}

URL: http://journals.openedition.org/studifrancesi/7697

DOI: 10.4000/studifrancesi.7697

ISSN: 2421-5856

\section{Editore}

Rosenberg \& Sellier

\section{Edizione cartacea}

Data di pubblicazione: 1 décembre 2009

Paginazione: 664

ISSN: 0039-2944

\section{Notizia bibliografica digitale}

Gian Luigi Di Bernardini, «Léon Blum - André Gide, Correspondance 1890-1957», Studi Francesi [Online], 159 (LIII | III) | 2009, online dal 30 novembre 2015, consultato il 09 janvier 2021. URL: http:// journals.openedition.org/studifrancesi/7697 ; DOI: https://doi.org/10.4000/studifrancesi.7697

\section{Questo documento è stato generato automaticamente il 9 janvier 2021}

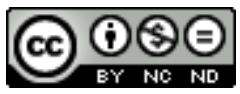

Studi Francesi è distribuita con Licenza Creative Commons Attribuzione - Non commerciale - Non opere derivate 4.0 Internazionale. 


\section{Léon Blum - André Gide, Correspondance 1890-1951}

Gian Luigi Di Bernardini 


\section{NOTIZIA}

LÉON BLUM - ANDRÉ GIDE, Correspondance 1890-1951, Lyon, Presses Universitaires de Lyon, 2008 , pp. 215.

La pubblicazione della corrispondenza tra André -Gide et Léon Blum, avvenuta dietro suggerimento di Pierre Masson (direttore del Centre d'études gidiennes di Nantes fino a non molto tempo fa), illumina il rapporto tra due personalità notevoli della Francia della Terza Repubblica. Come viene ricordato nell'Introduction (pp. 9-14), il rapporto tra lo scrittore e l'uomo politico di sinistra comincia sui banchi di scuola, ma decolla con difficoltà e resta difficile fino al primo dopoguerra. Raggiunta una notorietà considerevole nei rispettivi campi, e grazie all'adesione sempre più decisa di -Gide a idee di sinistra, questa relazione si trasforma in vera amicizia.

Occorre ricordare come alcune lettere di questa corrispondenza siano state in precedenza oggetto di pubblicazioni parziali e come gli studiosi se ne siano varie volte avvalsi. Proprio per questa ragione la pubblicazione della corrispondenza integrale (eccezion fatta per alcune lettere non ritrovate) costituisce un documento di notevole importanza per gli specialisti dell'opera gidiana.

3 La fluttuazione delle relazioni tra -Gide e Blum, dovute essenzialmente a ragioni di carattere estetico-letterario (Blum si orienta progressivamente verso la nozione di "arte utile", evidentemente in totale contrasto con il concetto gidiano di "gratuità") è alla base delle caratteristiche stesse di questo volume. Il numero esiguo di lettere (57 in totale, di cui 33 di Blum e 24 di -Gide), infatti, unito alla necessità di chiarire una consistente serie di sottintesi, spiega la ragione per la quale si trovano, tra una lettera e l'altra, dei veri e propri capitoli di raccordo. Ne risulta un libro di lettura scorrevole e che agevola l'accesso anche al lettore meno competente. 